\title{
Weight Cycling and Its Cardiometabolic Impact
}

\author{
Eun-Jung Rhee* \\ Department of Endocrinology and Metabolism, Kangbuk Samsung Hospital, Sungkyunkwan University School of Medicine, Seoul, Korea
}

\begin{abstract}
Dieting has multiple meanings including "intentional weight loss" or "a specific eating pattern." Although obesity is considered a deleterious health problem worldwide, there are many problems caused by "too strict" weight control and the need for excessive leanness. Many people with normal weight want to lose weight, and they repeat losing and gaining weight multiple times through their lives. This is called "weight cycling." Recent studies report not just the negative impact of being obese, but also the danger of weight cycling for cardiometabolic health. Many experimental studies support that weight cycling might cause fluctuations in cardiovascular risk factors, such as blood pressure, heart rate, sympathetic activity, and circulating levels of glucose, lipids and insulin. These repeated overshoots above normal values during periods of weight regain put an additional stress on the cardiovascular system. This paper reviews current evidence for the effects of weight cycling on cardiometabolic health.
\end{abstract}

Key words: Weight cycling, Cardiovascular disease, Yo-yo effect, Diet

\author{
Received August 7, 2017 \\ Reviewed August 20, 2017 \\ Accepted September 25, 2017 \\ ${ }^{*}$ Corresponding author \\ Eun-Jung Rhee \\ (ii) \\ https://orcid.org/0000-0002-6108-7758 \\ Department of Endocrinology and \\ Metabolism, Kangbuk Samsung Hospital, \\ Sungkyunkwan University School of \\ Medicine, 29 Saemunan-ro, Jongno-gu, \\ Seoul 03181, Korea \\ Tel: $+82-2-2001-2485$ \\ Fax: +82-2-2001-1588 \\ E-mail: hongsiri@hanmail.net
}

\section{INTRODUCTION}

The world is suffering from the deleterious effect of obesity. According to a report from the World Health Organization ${ }^{1}$, the prevalence of overweight and obesity is estimated to reach over $30 \%$ worldwide in 2014. Due to the marked increase in obese individuals, people are also suffering from diseases caused by obesity, such as diabetes, ischemic heart disease, hyperlipidemia, and even cancer. $^{2,3}$ Therefore, many academic associations investigating cardiometabolic diseases declare the real war is against obesity.

However, $70 \%$ of the world's population is in the normal weight range or underweight. However, thanks to the media or the desire for a slim figure, young people and even adolescents feel an urge to diet even though they are of normal weight. "Dieting" is usually defined in two broad ways: "the practice of eating food in a regulated fashion to decrease, maintain, or increase body weight" or "restricting oneself to small amounts or special kinds of food in order to lose weight." ${ }^{3,5}$ Repeated dieting —in the latter meaning — exposes subjects to weight loss and weight regain, that is, "weight cycling." Weight loss in obese subjects should affect their health positively; however, the effects of weight regain in these subjects are not wellknown, especially with respect to their cardiometabolic health.

"Yo-yo dieting" or the "yo-yo effect," also known as weight cycling, is a term first coined by Kelly D. Brownell at Yale University, in reference to the cyclical loss and gain of weight, resembling the up-down motion of a yo-yo, according to Wikipedia. ${ }^{6,7}$ In this review, evidence from the literature for the cardiometabolic effects of weight cycling is discussed.

\section{Who are at risk for weight cycling?}

Generally speaking, the prevalence of dieting has increased in the last several decades. Between 1950 and 1966, about 14\% of women and $7 \%$ of men in the U.S. reported that they had tried to lose weight. ${ }^{8,9}$ In the late 1980 s, approximately $40 \%$ of women and $25 \%$ 
of men were trying to lose weight, and during the 1990s, $44 \%$ of women and $29 \%$ of men attempted to lose weight. ${ }^{10,11}$ In the 20032008 National Health and Nutrition Examination Survey (NHANES), $57 \%$ of women and $40 \%$ of men in the U.S. reported desiring to weigh less. ${ }^{12}$ These numbers were slightly lower in European studies, but showed a similar trend in that a considerable proportion of men and women were dieting. ${ }^{13,14}$ All studies report women are more likely to diet than men. However, long-term studies report that people who diet to lose weight rarely succeed in maintaining the lost weight and make repeated attempts; thus, exposing them to the danger of weight cycling. ${ }^{15,16}$

As dieting is so common, the likelihood of regaining the lost weight is also high; therefore, the prevalence of weight cycling is high. ${ }^{17}$ Although studies that report the prevalence of weight cycling show high variability, it is assumed to range between $20 \%-$ $35 \%$ in men and $20 \%-55 \%$ in women. ${ }^{18,19}$ The problem with these wide variations in results is due to the recruitment of different populations and the lack of a universally accepted definition of weight cycling. ${ }^{20,21}$ The length, amplitude, number of cycles, intentionality, and objectivity of the characterization of weight cycling could be variables for defining weight cycle across different study populations. For example, in the Nurses' Health Study (NHS) II that enrolled 46,224 normotensive women, women showed huge variations in the number of weight loss attempts (one to three times over 4 years) and the amount of weight lost (2.25 to more than 4.5 $\mathrm{kg}) .{ }^{19}$ There are significant differences in the amount of weight lost, and the definitions of weight cycling across different studies performed in different populations.

As for the prevalence of dieting according to weight status, the study results are beyond our expectations. It is clear that obese and overweight people are more likely to attempt weight loss, and thus are more prone to be exposed to weight cycling. In a survey performed in Denmark, 54\% of overweight and $77 \%$ of obese people reported weight loss attempts at least once in their lives. ${ }^{22}$ However, it is becoming clearer that not only obese or overweight people are at risk for weight cycling, but this also affects lean people of normal weight, and even underweight and younger subjects. Interestingly, results from two national databases in the U.S. showed that there is now an increase in the proportion of normal weight individuals who seek to lose weight. ${ }^{23}$ Whether this could be a serious health problem or not has to be examined further.

This excessive desire for losing weight affects not only adults but also young and old people. Multiple studies performed in young adolescents and young girls showed that around $40 \%-50 \%$ of young girls want to lose weight and want to become like media figures. These misperceptions are known to be driven by maternal and paternal encouragement to diet at early ages. ${ }^{24,25}$ The rate of preoccupation with body weight leading to dieting and weight cycling are also high in older women. ${ }^{26}$ In a study from NHANES, the prevalence of older people ( $\geq 55$ years) who desired to weigh less was almost similar to that seen in younger people ( $<55$ years), around $70 \%$ vs. $75 \%$ among women and $59 \%$ vs. $54 \%$ among men. ${ }^{12}$ Unlike the situation in younger people, older people are particularly vulnerable to nutritional deficiencies and sarcopenic obesity that could be caused by excessive weight loss, which may be a health threat for them.

Apart from the general population, there are people who have to stay thin due to their occupation and professions. Ballerinas, dancers, top models, and entertainers are those for whom a slim image is professionally necessary. ${ }^{27,28}$ Movie actors or actresses often engage in marked intentional weight loss to embody specific characters. Slimming is also common among athletes involved in sports that compete according to weight category, such as weightlifting and combat sports, or who might benefit from a light body for performing gravitational sports (ski jumping). These participants are prone to weight cycling and are at high risk for developing eating disorders. $^{28}$

\section{The mechanisms for the deleterious impact of weight cycling}

Although the exact mechanisms underlying weight cycling on health outcomes are not clear, two hypotheses address this phenomenon: the "repeated overshoot" and increased visceral energy repartitioning hypotheses. ${ }^{17,29}$

Weight cycling could cause enhanced weight gain in the calorie excess period of weight fluctuation. ${ }^{30,31}$ What's more interesting is that these effects are more prominent in initially normal-weight subjects compared to those who are overweight or obese. ${ }^{32}$ For example, in a recent analysis of a large population-based cohort of mostly normal weight adolescents followed through young adult- 


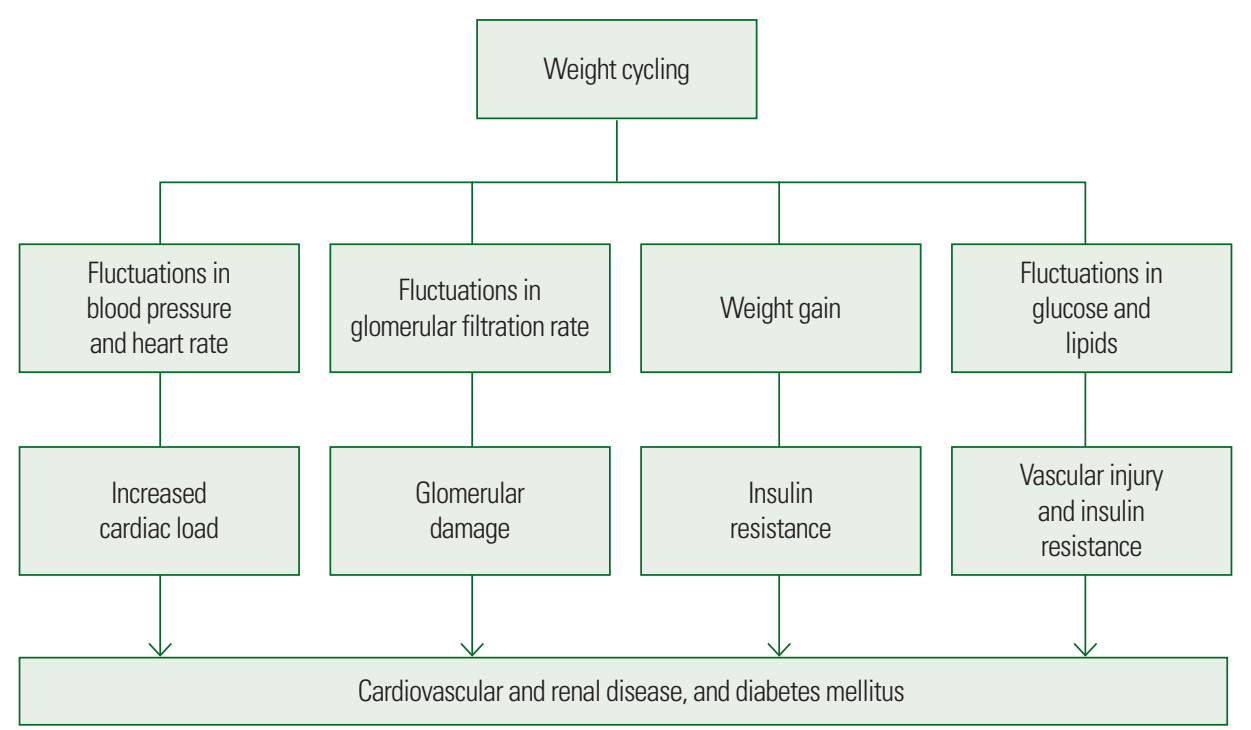

Figure 1. The mechanisms of weight cycling effects on cardiometabolic health outcomes.

hood, a dose-dependent association between the number of lifetime intentional weight losses and body mass index (BMI) gain was reported, but also the rate of weight gain was higher among those in the lowest baseline BMI category compared to those in the middle or higher BMI category.

Weight fluctuation is known to lead to hyperinsulinemia and insulin resistance (Fig. 1). ${ }^{33,34}$ It is also known to cause hypertension and dyslipidemia. ${ }^{35}$ These phenomena could be explained by the repeated overshoot hypothesis. ${ }^{17}$ Sustained fluctuation in energy balance as it occurs during weight cycling can lead to potential fluctuations in cardiovascular risk factors, such as blood pressure, heart rate, cardiac workload, sympathetic activity, blood glucose and lipids, and may increase above normal values during periods of weight regain. The stress induced by repeated overshoot of these risk variables during food excess periods may not be compensated for by a reduction in risk factors during weight loss periods. As a consequence, the fluctuations in risk factors put an extra load on the heart and may lead to vascular injury (Fig. 1). Indeed, higher than normal values for risk factors were seen during weight regain after a period of food restriction. ${ }^{36}$

Another mechanism that is assumed to be plausible is changes in energy partitioning after weight cycling. In a cross-sectional survey that was assessed by self-questionnaire and interview, a history of weight cycling was independently associated with higher BMI and waist-hip ratio, suggesting an association between weight cycling and abdominal obesity. In another study performed in young overweight and obese adults, weight regain after weight loss did not adversely affect body fat distribution. ${ }^{37,38}$ However, weight loss-associated adaptations in resting energy expenditure were impaired in weight cyclers. In this study, the authors concluded that the reconstitution of skeletal muscle in the trunk during spontaneous 6 months weight regain lagged behind that seen in the extremities, in line with the study by Byrne et al. ${ }^{39}$, who found a preferential regain of lean mass in the limbs compared with the trunk in weight regaining subjects. These results suggest that the repartitioning of fat and lean mass after weight cycling could have affected cardiometabolic risk factors, and thus may affect cardiometabolic health outcomes.

\section{Long-term adverse health consequences of weight cycling}

There are concerns about the long-term adverse health consequences of weight cycling. Repeated dieting and weight cycling have been implicated in an increased risk for eating disorders, other psychological disorders, and multiple comorbidities including obesity, type 2 diabetes, hypertension, cancer, bone fractures, and increased mortality. However, the effects of weight cycling on health outcomes are a source of debate..$^{20,40}$

The most commonly debated association is with type 2 diabetes and cardiovascular morbidity and mortality. Earlier studies concluded that weight fluctuations were associated with an increased risk for cardiometabolic morbidity or mortality, which contrasted 
with subsequent studies that failed to show a significant association. ${ }^{41,42}$ For example, in a 6-year follow-up study from NHS II, the association between weight cycling and higher rates of type 2 diabetes was no longer significant after adjustment for overall weight status. ${ }^{19}$ However, in a recent 9-year follow-up study in Finnish men smokers aged 50-69 years, subjects with large weight fluctuations showed a significantly increased risk for type 2 diabetes compared to those with stable weight. ${ }^{43}$ In a very recent study performed in 9,509 participants in a Treating to New Targets trial, body weight fluctuation was significantly associated with higher mortality and a higher rate of cardiovascular events independent of traditional cardiovascular risk factors, confirming the deleterious effects of weight fluctuation on cardiovascular events development. ${ }^{44}$ These discrepancies could be attributed to the different study populations, and the methods used for the assessment of weight cycling. In addition, the absence of a consensus on a standard definition for weight cycling could be the biggest challenge for future studies in this field.

\section{CONCLUSION}

Due to the slim figures appearing in social media, even young adolescents are exposed to repetitive diet and weight cycling. However, weight cycling has many deleterious health consequences. Losing weight is important for cardiometabolic health; however, maintaining stable body weight might be more important according to this review of the literature. It is important to maintain a balance between losing weight and weight fluctuations to stay healthy cardiometabolically.

\section{CONFLICTS OF INTEREST}

The author declares no conflict of interest.

\section{REFERENCES}

1. World Health Organization. Overweight and obesity [Internet]. Geneva: World Health Organization; c2017 [cited 2017 Oct 28]. Available from: http://www.who.int/gho/ncd/risk_ factors/overweight/en/
2. Jarolimova J, Tagoni J, Stern TA. Obesity: its epidemiology, comorbidities, and management. Prim Care Companion CNS Disord 2013;15:PCC.12f01475.

3. Gallagher EJ, LeRoith D. Obesity and diabetes: the increased risk of cancer and cancer-related mortality. Physiol Rev 2015; 95:727-48.

4. Wikipedia contributors. Dieting: from Wikipedia, the free encyclopedia [Internet]. San Francisco, CA: Wikimedia Foundation; [cited 2017 Aug 2]. Available from: https://en.wikipedia. org/w/index.php?title=Dieting\&oldid=807557463

5. Oxford dictionaries. Language matters: verb (diets, dieting, dieted) [Internet]. Oxford: Oxford University Press; [cited 2017 Aug 2]. Available from: http://www.oxforddictionaries.com/ us/definition/american_english/diet

6. Wikipedia contributors. Yo-yo effect: from Wikipedia, the free encyclopedia [Internet]. San Francisco, CA: Wikimedia Foundation; [cited 2017 Aug 2]. Available from: https://en.wikipedia.org/w/index.php?title=Yo-yo_effect\&oldid $=764898540$

7. Montani JP, Schutz Y, Dulloo AG. Dieting and weight cycling as risk factors for cardiometabolic diseases: who is really at risk? Obes Rev 2015;16 Suppl 1:7-18.

8. Dwyer JT, Mayer J. Potential dieters: who are they? J Am Diet Assoc 1970;56:510-4.

9. Jeffery RW, Folsom AR, Luepker RV, Jacobs DR Jr, Gillum RF, Taylor HL, et al. Prevalence of overweight and weight loss behavior in a metropolitan adult population: the Minnesota Heart Survey experience. Am J Public Health 1984;74:349-52.

10. Williamson DF, Serdula MK, Anda RF, Levy A, Byers T. Weight loss attempts in adults: goals, duration, and rate of weight loss. Am J Public Health 1992;82:1251-7.

11. Serdula MK, Williamson DF, Anda RF, Levy A, Heaton A, Byers T. Weight control practices in adults: results of a multistate telephone survey. Am J Public Health 1994;84:1821-4.

12. Yaemsiri S, Slining MM, Agarwal SK. Perceived weight status, overweight diagnosis, and weight control among US adults: the NHANES 2003-2008 Study. Int J Obes (Lond) 2011;35: 1063-70.

13. Lahti-Koski M, Seppänen-Nuijten E, Männistö S, Härkänen T, Rissanen H, Knekt P, et al. Twenty-year changes in the prevalence of obesity among Finnish adults. Obes Rev 2010;11:171-6. 
14. Julia C, Péneau S, Andreeva VA, Méjean C, Fezeu L, Galan P, et al. Weight-loss strategies used by the general population: how are they perceived? PLoS One 2014;9:e97834.

15. Methods for voluntary weight loss and control. NIH Technology Assessment Conference Panel: Consensus Development Conference, 30 March to 1 April 1992. Ann Intern Med 1993; 119(7 Pt 2):764-70.

16. Mann T, Tomiyama AJ, Westling E, Lew AM, Samuels B, Chatman J. Medicare's search for effective obesity treatments: diets are not the answer. Am Psychol 2007;62:220-33.

17. Montani JP, Viecelli AK, Prévot A, Dulloo AG. Weight cycling during growth and beyond as a risk factor for later cardiovascular diseases: the 'repeated overshoot' theory. Int J Obes (Lond) 2006;30 Suppl 4:S58-66.

18. Foreyt JP, Brunner RL, Goodrick GK, Cutter G, Brownell KD, St Jeor ST. Psychological correlates of weight fluctuation. Int J Eat Disord 1995; 17:263-75.

19. Field AE, Byers T, Hunter DJ, Laird NM, Manson JE, Williamson DF, et al. Weight cycling, weight gain, and risk of hypertension in women. Am J Epidemiol 1999;150:573-9.

20. Weight cycling. National task force on the prevention and treatment of obesity. JAMA 1994;272:1196-202.

21. Mehta T, Smith DL Jr, Muhammad J, Casazza K. Impact of weight cycling on risk of morbidity and mortality. Obes Rev 2014;15:870-81.

22. Bendixen H, Madsen J, Bay-Hansen D, Boesen U, Ovesen LF, Bartels EM, et al. An observational study of slimming behavior in Denmark in 1992 and 1998. Obes Res 2002;10:911-22.

23. Mikolajczyk RT, Maxwell AE, El Ansari W, Stock C, Petkeviciene J, Guillen-Grima F. Relationship between perceived body weight and body mass index based on self- reported height and weight among university students: a cross-sectional study in seven European countries. BMC Public Health 2010; 10:40.

24. Ojala K, Vereecken C, Välimaa R, Currie C, Villberg J, Tynjälä $\mathrm{J}$, et al. Attempts to lose weight among overweight and nonoverweight adolescents: a cross-national survey. Int J Behav Nutr Phys Act 2007;4:50.

25. Currie C, Zanotti C, Morgan A, Currie D, de Looze M, Roberts $\mathrm{C}$, et al. Social determinants of health and well-being among young people. Health behaviour in school-aged children (HBSC) study: international report from the 2009/2010 survey. Copenhagen: WHO Regional Office for Europe; 2012.

26. Marshall C, Lengyel C, Utioh A. Body dissatisfaction among middle-aged and older women. Can J Diet Pract Res 2012;73: e241-7.

27. Koutedakis Y, Jamurtas A. The dancer as a performing athlete: physiological considerations. Sports Med 2004;34:651-61.

28. Thone RR. Fat: a fate worse than death? Women, weight, and appearance. New York (NY): Haworth Press; 1997.

29. Sundgot-Borgen J, Meyer NL, Lohman TG, Ackland TR, Maughan RJ, Stewart AD, et al. How to minimise the health risks to athletes who compete in weight-sensitive sports review and position statement on behalf of the Ad Hoc Research Working Group on Body Composition, Health and Performance, under the auspices of the IOC Medical Commission. Br J Sports Med 2013;47:1012-22.

30. Bosy-Westphal A, Kahlhöfer J, Lagerpusch M, Skurk T, Müller MJ. Deep body composition phenotyping during weight cycling: relevance to metabolic efficiency and metabolic risk. Obes Rev 2015;16 Suppl 1:36-44.

31. Zhang H, Tamakoshi K, Yatsuya H, Murata C, Wada K, Otsuka $\mathrm{R}$, et al. Long-term body weight fluctuation is associated with metabolic syndrome independent of current body mass index among Japanese men. Circ J 2005;69:13-8.

32. Saarni SE, Rissanen A, Sarna S, Koskenvuo M, Kaprio J. Weight cycling of athletes and subsequent weight gain in middleage. Int J Obes (Lond) 2006;30:1639-44.

33. Korkeila M, Rissanen A, Kaprio J, Sorensen TI, Koskenvuo M. Weight-loss attempts and risk of major weight gain: a prospective study in Finnish adults. Am J Clin Nutr 1999;70:965-75.

34. Pietiläinen KH, Saarni SE, Kaprio J, Rissanen A. Does dieting make you fat? A twin study. Int J Obes (Lond) 2012;36:45664.

35. Yatsuya H, Tamakoshi K, Yoshida T, Hori Y, Zhang H, Ishikawa $\mathrm{M}$, et al. Association between weight fluctuation and fasting insulin concentration in Japanese men. Int J Obes Relat Metab Disord 2003;27:478-83.

36. Willett WC, Manson JE, Stampfer MJ, Colditz GA, Rosner B, Speizer FE, et al. Weight, weight change, and coronary heart 
disease in women: risk within the 'normal' weight range. JAMA 1995;273:461-5.

37. Antic V, Dulloo A, Montani JP. Short-term (5-day) changes in food intake alter daily hemodynamics in rabbits. Am J Hypertens 2003;16:302-6.

38. Cereda E, Malavazos AE, Caccialanza R, Rondanelli M, Fatati G, Barichella M. Weight cycling is associated with body weight excess and abdominal fat accumulation: a cross-sectional study. Clin Nutr 2011;30:718-23.

39. Byrne NM, Weinsier RL, Hunter GR, Desmond R, Patterson MA, Darnell BE, et al. Influence of distribution of lean body mass on resting metabolic rate after weight loss and weight regain: comparison of responses in white and black women. Am J Clin Nutr 2003;77:1368-73.

40. Bosy-Westphal A, Schautz B, Lagerpusch M, Pourhassan M, Braun W, Goele K, et al. Effect of weight loss and regain on adipose tissue distribution, composition of lean mass and rest- ing energy expenditure in young overweight and obese adults. Int J Obes (Lond) 2013;37:1371-7.

41. Muls E, Kempen K, Vansant G, Saris W. Is weight cycling detrimental to health? A review of the literature in humans. Int J Obes Relat Metab Disord 1995;19 Suppl 3:S46-50.

42. Hamm P, Shekelle RB, Stamler J. Large fluctuations in body weight during young adulthood and twenty-five-year risk of coronary death in men. Am J Epidemiol 1989;129:312-8.

43. Peters ET, Seidell JC, Menotti A, Arayanis C, Dontas A, Fidanza F, et al. Changes in body weight in relation to mortality in 6441 European middle-aged men: the Seven Countries Study. Int J Obes Relat Metab Disord 1995;19:862-8.

44. Kataja-Tuomola M, Sundell J, Männistö S, Virtanen MJ, Kontto J, Albanes D, et al. Short-term weight change and fluctuation as risk factors for type 2 diabetes in Finnish male smokers. Eur J Epidemiol 2010;25:333-9. 